
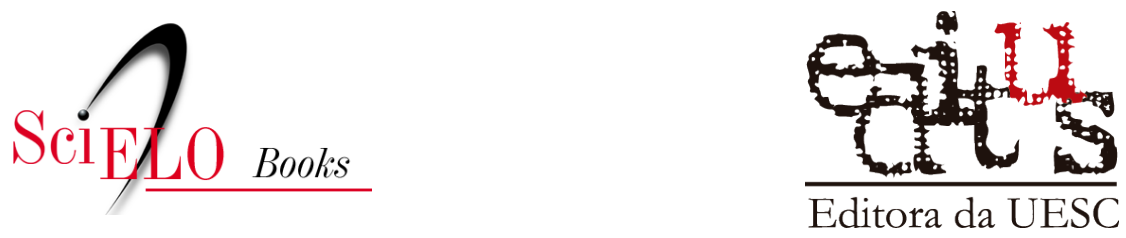

\title{
4 Os caminhos trilhados para a concretização do direito à memória quilombola
}

\author{
Raíssa Félix
}

\section{SciELO Books / SciELO Livros / SciELO Libros}

FÉLIX, R. Os caminhos trilhados para a concretização do direito à memória quilombola. In: Volta miúda: quilombo, memória e emancipação [online]. Ilhéus, BA: Editus, 2020, pp. 69-81. Transfluência series. ISBN: 978-65-86213-14-0. https://doi.org/10.7476/9786586213317.0005.

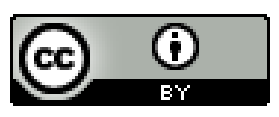

All the contents of this work, except where otherwise noted, is licensed under a Creative Commons Attribution 4.0 International license.

Todo o conteúdo deste trabalho, exceto quando houver ressalva, é publicado sob a licença Creative Commons Atribição 4.0.

Todo el contenido de esta obra, excepto donde se indique lo contrario, está bajo licencia de la licencia Creative Commons Reconocimento 4.0. 


\section{4}

\section{Os caminhos trilhados}

para a concretização do direito à memória quilombola

A posição no rol dos direitos humanos evidencia que o exercício da vivificação ou preservação da memória é requisito para a concretização da humanidade do ser ou, em outros termos, da dignidade da pessoa humana - princípio estrutural do ordenamento jurídico brasileiro. O predicado "fundamental" é incorporado ao direito à memória por ser expressamente tutelado pela Constituição Federal. O conceito desse direito está sendo referido em sua acepção histórica, pois, dizer da existência de um direito à memória é abrir caminhos a que cada brasileira e brasileiro perquira sua verdadeira identidade, muito além do discurso hegemônico.

Por ser o direito à memória de caráter humano/fundamental, a correlação entre memória e identidade é inevitável, assim como a rediscussão da liberdade nos tempos em que os grilhões já não são mais visíveis e as relações 
hierarquizadas impõem uma cultura homogeneizante. Ao situar a discussão neste contexto, a memória se apresenta de forma politizada e cujas implicações ultrapassam o viés teórico-filosófico, alcançando o processo de autoafirmação dos sujeitos e o necessário repensar da liberdade.

Isto posto, ratifica-se que o resgate da origem histórico-cultural do povo brasileiro é instrumento para a consecução da sua dignidade e essencial, portanto, ao seu reconhecimento enquanto sujeito-cidadão. Por consequência, promover a ausculta e transliteração das memórias de uma comunidade remanescente quilombola localizada no extremo sul do estado da Bahia reveste-se de importância social enquanto produção de conhecimento pela, para e acerca da localidade, com vistas à documentação de fatos históricos e culturais presentes na memória dos anciãos, assim como por instrumentalizar o ensino de história na rede regular de ensino em uma perspectiva decolonial.

Ao discutir a memória como conceito jurídico, político e sociológico, o termo se preenche, assume feição imperativa sob a pena de ser o caráter humano olvidado em sua inteireza. Tal qual o direito à memória, o direito à educação também se situa no âmbito dos direitos humanos, visto, portanto, como pressuposto para a dignidade humana. Se do ponto de vista histórico-sociológico, a memória é elemento fundante da identidade e a Educação é direito social elementar, dever do Estado, a interseção desses conceitos implica refletir a formação do sujeito. E é consequente, também, a indagação sobre a sua manifesta (e precária) liberdade, tutelada pelo Estado de direito que é, ao mesmo tempo, precursor do processo educacional formativo do 
cidadão recorrentemente executado como mecanismo de alfabetização desmemoriada.

Considerando-se uma comunidade quilombola, investigar a efetivação do direito fundamental à memória gravita nos termos da sua emancipação e resistência aos ditames sociopolíticos elitizados e limitadores, advindos de uma sociedade que é concebida à margem da sua história - nisto inclui-se a marginalização da população negra - e de um Estado que atua tardiamente na equalização desse passivo. A Educação e a Memória são direitos constitucionais - e linhas globais abissais -, sua interação imprime o necessário repensar histórico e cultural apreendido e imposto pelo discurso hegemônico. Neste ponto, fundamental é a promoção de instrumentos e práticas educacionais, a fim de contribuir com a cisão da colonialidade.

A busca pela efetivação do direito à memória quilombola, numa perspectiva atinente às epistemologias do sul, demandou múltiplas ferramentas, no âmbito da pesquisa qualitativa e investigação social. Da pesquisa bibliográfica e historiográfica, estudos exploratórios, à metodologia central de produção da pesquisa a partir da história oral. A pesquisa bibliográfica ou revisão de literatura foi um recurso fundamental para a compreensão prévia do(s) campo(s) em que o tema se insere, especialmente para a realização das entrevistas - "o primeiro ponto é a preparação de informações básicas, por meio da leitura e de outras maneiras" (THOMPSON, 1992, p. 254). As informações contextuais servem à localização científica da abordagem e conhecimento, pelo pesquisador, acerca de teorias, controvérsias e lacunas a serem exploradas (FLICK, 2009, p. 62), daí a importância (e 
6. Em Memórias da Plantação - episódios de racismo quotidiano, livro oriundo da trajetória de mestrado de Grada Kilomba, a autora descreve suas escolhas metodológicas na seção "Decidindo pela pesquisa centrada em sujeitos", elucidando o seu trabalho como "um espaço para performar a subjetividade, para reconhecer mulheres negras, em particular, e pessoas negras em geral, como sujeitos desta sociedade - em

todos os sentidos reais da palavra" (KILOMBA, 2019, p. 81). À sua semelhança, compreendemos que o processo de decisão metodológica é conteúdo teórico elementar à

compreensão deste livro como instrumento decolonial. necessidade) de tomá-la à primeira mão para o desenvolvimento das etapas posteriores.

O estudo em campo foi realizado de maneira contínua, uma vez que o processo interativo entre pesquisadora e público alvo é necessário à consecução dos objetivos da pesquisa (FLICK, 2009, p. 110). Tal estudo foi fundamental à consecução do método da história oral ${ }^{6}$ que norteou a coleta de dados, propiciando desde a abordagem inicial dos sujeitos da pesquisa à viabilização das entrevistas, realizadas individualmente (MARTINS; THEÓPHILO, 2007, p. 72). Estas foram precedidas do processo de sensibilização dos participantes e coleta preliminar de dados, prévia à preparação do roteiro "mapeando o campo e colhendo ideias e informações", como ensinou Thompson (1992, p. 254).

A escuta orientada visou à compreensão da comunidade e do seu percurso histórico, visto que para Paul Thompson (1992, p. 197), “toda fonte histórica derivada da percepção humana é subjetiva, mas apenas a fonte oral permite-nos desafiar essa subjetividade: descolar as camadas de memória, cavar fundo em suas sombras, na expectativa de atingir a verdade oculta". Assim, as falas captadas e as leituras sobre/ durante o processo de entrevista gozaram de espaço e importância na constituição do trabalho e as observações foram registradas em caderno de campo (ALBERTI, 2005, p. 100), tais como: descrição das entrevistas, dificuldades e interrupções, informações obtidas e que não foram gravadas, reação dos entrevistados, como se deu a finalização da entrevista, entre outros.

Para a realização das entrevistas, utilizou-se a técnica semipadronizada, a fim de permitir o desenvolvimento 
da abordagem subjetiva e sua reflexão (FLICK, 2009, p. 148154), do tipo temática, versando prioritariamente sobre a participação do entrevistado no tema escolhido, conforme Alberti (2007, p. 175). Considerando que um questionário detalhado e preciso limitaria o desenvolvimento do discurso da testemunha, e que se "for deixada totalmente livre, há o risco de se afastar do tema tratado", Chantal de Tourtier-Bonazzi (2006, p. 237) também considera a entrevista semiestruturada mais adequada à captação da história oral, como se pleiteava.

$O$ roteiro geral de entrevistas foi elaborado com base na pesquisa exaustiva sobre o tema, com a "síntese das questões levantadas durante a pesquisa em fontes primárias e secundárias", com vistas a orientar as atividades posteriores, sobretudo a preparação dos roteiros individuais (ALBERTI, 2005, p. 83). Respeitadas as peculiaridades da trajetória e experiências de cada entrevistado, os roteiros foram elaborados sob uma base comum, permitindo que se identificasse "divergências, recorrências ou ainda concordâncias entre as diferentes versões obtidas ao logo da pesquisa, aprofundando-se as possibilidades de análise do acervo" (ALBERTI, 2005, p. 84). Então, a elaboração dos roteiros individuais se deu após a aplicação do roteiro geral, a partir do qual foram listados temas sensíveis aos sujeitos entrevistados, que fui identificando desde os primeiros diálogos.

Verena Alberti (2005, p. 18) se refere à história oral como "método-fonte-técnica" que "privilegia a realização de entrevistas com pessoas que participaram de, ou testemunharam, acontecimentos, conjunturas, visões de mundo", aspecto de relevância maior que se espera alcançar neste trabalho. Segundo ela, "trata-se de estudar acontecimentos históricos, 
instituições, grupos sociais, categorias profissionais, movimentos, conjunturas etc. à luz de depoimentos de pessoas que deles participaram ou os testemunharam" (ALBERTI, 2005, p. 18), e, por isso, a pesquisa foi desenvolvida por meio de entrevistas gravadas com anciãs/os quilombolas que guardam memórias sobre os jeitos de ser e viver dos antepassados próximos. No que tange ao fator etário, Alberti (1992, p. 85) considera preferível começar a entrevistar os mais idosos, em razão da relevância de se alcançar fatos pretéritos, cujos aspectos e sentidos estejam ocultos ou tenham sido invisibilizados, especialmente para a realização desta pesquisa.

Ao prefaciar o livro Memória e Sociedade: lembranças de velhos, escrito por Ecléa Bosi, Marilena Chauí adverte que

\begin{abstract}
a memória não é oprimida apenas porque lhe foram roubados suportes materiais, nem só porque o velho foi reduzido à monotonia da repetição, mas também porque uma outra ação, mais daninha e sinistra, sufoca a lembrança: a história oficial celebrativa cujo triunfalismo é a vitória do vencedor a pisotear a tradição dos vencidos. (CHAUí, 1994, p. 19).
\end{abstract}

E, por considerar a memória como a ponte entre presente e passado, Bosi defende a sua interferência no processo "atual" das representações, sendo responsável por deslocar percepções e ocupar o espaço da consciência, a "memória aparece como força subjetiva ao mesmo tempo profunda e ativa, latente e penetrante, oculta e invasora" (BOSI, 1994, p. 46-47) e, exatamente por isso, é elemento imprescindível à proposta de descolonização de saberes. 
A receptividade e simplicidade dos moradores de Volta Miúda tornavam incômoda a percepção do egoísmo e espírito defensivo comuns à vida urbana resultantes dos princípios da modernidade-racionalidade. Na miudeza ignorada, mundos de sentimentos afloravam em olhares, tons e ritmos sonoros, na apreensão da vida que não possui fim em si mesma, mas que se realiza em comunidade. Na Volta Miúda memorada não se percebia espaço para o individualismo, as narrativas evocavam um sentido coletivo das experiências e, mesmo quando nos verbos de ação o "eu" predominava, o sujeito não existia no mundo para si ou dissociado da sua responsabilidade para com os fazeres da comunidade - sejam eles religiosos, culturais ou quotidianos.

As/os participantes da pesquisa foram selecionados segundo os critérios: geográfico e de pertencimento, visto que se buscou moradores da Comunidade Quilombola de Volta Miúda, Caravelas/BA; etário, posto que, tendo em vista o caráter memorial da pesquisa, à guisa de alcançar informações sobre a história e cultura da comunidade, buscou-se identificar os indivíduos com idade superior a 60 anos em virtude da vivência e repertório referentes a práticas e experiências anteriores aos mais novos, cujos aspectos e sentidos estejam ocultos ou tenham sido invisibilizados; gênero, pois também objetivou-se alcançar equilíbrio entre homens e mulheres entrevistados e perfilados. O consentimento tratou-se de critério procedimental, também considerado como critério de inclusão, haja vista que a participação dos sujeitos na pesquisa implicaria a utilização/publicação das informações e imagens concedidas/ obtidas. A concordância foi dada por todas/os e, ao todo, cinco 
7. Conforme os parâmetros éticos adotados pela área das Ciências Humanas, Sociais e Sociais Aplicadas e pelo Comitê de Ética da Universidade Federal do Sul da Bahia (UFSB) mulheres e cinco homens foram perfiladas/os. As entrevistas aconteceram em locais escolhidos pelas/os próprios participantes, sendo a maioria em suas próprias casas, o que garantiu um ambiente confortável e familiar, deixando as/os entrevistadas/os mais à vontade na condução do processo.

No que tange às questões formais-legais, as entrevistadas e entrevistados assentiram formalmente em participar da pesquisa, mediante assinatura de Termo de Consentimento Livre e Esclarecido para as fontes que, além de ser produzido numa linguagem acessível ${ }^{7}$, foi por mim lido e explicado. Na qualidade de pesquisadora, fui à comunidade e abordei os sujeitos, individualmente, em suas residências e a fim de apresentar-me, como mestranda do Programa de Pós-Graduação em Ensino e Relações Étnico-Raciais da Universidade Federal do Sul da Bahia, e explicar a motivação da visita e da pesquisa, tema e objetivos, convidando-os à integração na qualidade de sujeitos participantes, entrevistada/os a serem perfilada/os.

Após a apresentação do roteiro geral das entrevistas, expliquei sobre a necessidade de consentimento expresso para a participação e cessão do direito de uso sobre o conteúdo e imagens a serem fornecidos no seu decorrer e, diante da plena compreensão por parte do/a pretenso/a entrevistado/a sobre os aspectos elementares da pesquisa e a implicação do seu consentimento e fornecê-lo de forma livre e esclarecida, as entrevistas foram acontecendo conforme a disponibilidade de cada um dos/as entrevistados/as. Todos os encontros aconteceram na própria comunidade, a grande maioria na residência dos próprios entrevistados. Os registros das entrevistas foram feitos em áudio e fotografias, a 
gravação em vídeo foi inviabilizada pela ausência de equipamentos adequados à obtenção de uma qualidade razoável.

Interessante notar as peculiaridades dos relatos, quanto às diferenças de perspectivas para análise e relembrar dos fatos, enquanto para os homens foi marcante o eixo centrado nas ocupações laborais, as mulheres expressavam apreço preponderante às relações familiares. Os procedimentos foram escolhidos a fim de possibilitar a captura destas nuanças, tal como o diálogo inicial com as mulheres, que ao ser, geralmente, precedido de falas como "eu não sei falar", "eu não sou boa nisso", "meu marido [ou irmão ou cunhado] é melhor para falar com você", faz denotar uma autoestima minorada ante a cultura/organização sexista ${ }^{8}$.

Nos dizeres de Ana Lugão Rios e Hebe Mattos (2005, p. 29), as memórias forjadas no âmbito do cativeiro, ou a partir dele, têm o condão de recuperar a historicidade dos diferentes processos de desestruturação da ordem escravista e de "desnaturalizar a noção de raça, percebendo as categorias e identidades raciais como construções sociais historicamente determinadas". Carlos Vogt e Peter Fry (1996, p. 25) criticam a tergiversação sobre o fenômeno da "resistência cultural", alegando que a resistência dos traços culturais afrodescendentes "não é um processo simples que se dá no confronto entre duas culturas imutáveis no tempo", pois, ao conceber a resistência como "sintoma de certa pujança metafísica das culturas africanas", pretere-se a consciência quanto aos enfrentamentos entre grupos, categorias e indivíduos, "para quem a cultura orienta a ação política e é ao mesmo tempo uma arma usada para empreendê-la".
8. Isto se afirma sem olvidar a força e presença dessas mulheres dentro da própria comunidade - paradoxo que faz remeter a que a interpretação e instrumentalização das noções e palavras podem servir à ratificação ou retificação das fraturas e discrepâncias sociais. Quando os lugares sociais são lidos ao ponto da sua teorização e com a objetificação dos sujeitos, admite-se tais afastando-se a sua humanidade, projetase a subalternização. Quando o observador se coloca atrás do sujeito a fim de perceber a sociedade, permite-se a interpretação da sua racionalidadesensibilidade e, portanto, resistência ante a prática e discurso desumanizador. 
A compilação da oralidade em perfis biográficos foi estratégia pensada na perspectiva da luta antirracista, a fim de romper os muros da escola e do ensino formal, mas também nesse contra movimento científico. Reverenciando-se a Comunidade de Volta Miúda para leitura de uma personalidade coletiva lida a partir de trajetórias individuais, concretiza-se o direito a essas memórias negadas pelas oficialidades, hábil a desnaturalizar concepções histórico-culturais-identitárias de quilombolas, caravelenses, teixeirenses.

Os perfis biográficos, textos do gênero do jornalismo literário, pareceram-me hábeis à captação das nuanças histórico-culturais expressas nas trajetórias individuais das/os entrevistadas/os. Sua formatação sucinta e fluida, em geral, profunda, permitiu que a voz das/dos mesmas/os fosse preservada tanto quanto possível, com os alinhavos necessários à técnica da palavra da escrita. O jornalista e professor Sérgio Vilas Boas ensina que os perfis biográficos

\begin{abstract}
cumprem um papel importante que é exatamente gerar empatias. Empatia é a preocupação com a experiência do outro, a tendência a tentar sentir o que sentiria se estivesse nas mesmas situações e circunstâncias experimentadas pelo personagem. Significa compartilhar as alegrias e tristezas de seu semelhante, imaginar situações do ponto de vista do interlocutor. Acredito que a empatia também facilita o autoconhecimento (de quem escreve e de quem lê). (VILAS BOAS, 2003, p. 14).
\end{abstract}

Ao contextualizar a história e cultura afrodescendente da comunidade e, oportunamente, evidenciar aspectos relatados que tenham sido invisibilizados pelo discurso 
dominante, busquei preservar as marcas da oralidade. Isto porque, além do caráter narrativo-descritivo, este tipo textual nasce no âmbito das pesquisas qualitativas em Ciências Sociais no termo "Histórias de Vida", modalidade que "dá atenção total ou parcial às narrativas sobre as vidas de indivíduos ou de grupos sociais, visando humanizar um tema, um fato ou uma situação contemporânea" (VILAS BOAS, 2003, p. 16-17). E, num exercício máximo do compromisso com a relação de confiança estabelecida com as/os entrevistadas/ os, os perfis culminaram na preservação das histórias, identidades e sentimentos contados.

Concordando com o jornalista, a criação, a escrita, o discurso são processos multidimensionais que, como argumentado supra, possuem forte carga política, ainda que implicitamente. A escrita dos perfis biográficos foi um ato que corrobora a urgência das pautas relativas à justiça social no Brasil, e é também uma síntese de memória, conhecimento e sentimento - caractere incompatível às métricas da modernidade que, em seu discurso, coisifica e mina a humanidade dos seres.

Diálogos transcritos dispostos à mesa, lidos, escutados, uma, duas, três vezes... Foi este o ápice solitário da escritora - e, creio, daquelas/es que se põem a exercer o ofício -, a ebulição das vozes e a escolha das palavras a fim de que façam do texto não produto, ou resultado mas leitura por essência e manifesto por vocação. O amplo conteúdo abordado foi sendo lapidado à medida que percebi uma inclinação maior ou mais sensível de cada entrevistado/a em relação a determinado tema. Escrever os perfis foi um processo mais complexo e conflituoso do que esperava 
enfrentar. Escrever é um processo de escolha, se leio algo, o que me inquieta é o que ficou por existir, por ser verbalizado, transcrito. Volta Miúda me inspirava em muitos aspectos e, encontrar o caminho que me levava aos objetivos obliterados da minha pesquisa foi um processo árduo de lapidação... Sobretudo para quem, na compreensão da sua interseccionalidade, vê imbricadas as relações do ser que relata memórias e externaliza sentimentos, de forma que os "aspectos históricos e culturais da comunidade de Volta Miúda" resistiam ao cumprimento do trabalho, pois o excediam.

Os vínculos criados, fortalecidos, aumentavam a responsabilidade sobre o processo de escrita. Pois, o compromisso - antes apenas acadêmico/social - agora perpassava pela afetividade entre nós. A razão política que me trouxe até aqui sofreu essa catálise. A minha caminhada acadêmica, graduação como bolsista, especializações (a primeira também cursada graças a uma bolsa de estudos) e agora o mestrado, é, sobretudo, fruto de um processo de inclusão social de que fui beneficiária e que me informa o compromisso para com os meus pares. Esta é também uma forma em que resisto ativamente, na luta por equidade, por respeito e por justiça social. Cada perfil implicou uma ebulição de sentimentos diferentes, porque evocam, também, significados e experiências que remontam a pluriversos particulares de sentido. Como não poderia deixar de ser, a apresentação de cada perfil se firmou em um núcleo temático que, conforme Sérgio Vilas Boas (2003), pode se tratar de uma circunstância, lembrança, característica ou, até mesmo, da interação estabelecida para com a autora e do/a narrador/a com a sua memória. 
Pôr-me a escrever os perfis não causava medo, mas a responsabilidade desta tarefa obrigou-me ao exercício de transformá-la não no fim, mas em fundamento guia para a minha sensibilidade. Responsabilidade e compromisso para com os sujeitos, amigas e amigos e suas memórias. Para com aqueles seres indeterminados com quem pretendia comunicá-los. Para com a resistência que faz de mim instrumento orgânico em prol da justiça social, da equidade, liberdades e dignidades humanas. 